may be the very one which makes silver efficacious in the treatment of the disease.

The reason that ordinary clinical observation is of small scientific value is that it is impossible to control all the conditions and to keep the patient under constant supervision. Standish believes that these objections are obviated in such an isolation ward as the Gardner Building of the Massachusetts Charitable Eye and Ear Infirmary. Here the conditions surrounding the patient, he states, are absolutely under control. The cases selected for observation were cases of gonorrheal ophthalmia with clear cornea. Of 50 cases of ophthalmia neonatorum treated with silver nitrate corneal affection developed in 6 per cent. In 150 cases treated with protargol the cornea became infected in 3 per cent. In 201 cases treated with argyrol, the cornea became infected in 2 per cent. In adults the proportion of cases in which the cornea became infected was much greater, being about 42 per cent., but in only approximately 7.5 per cent. was the outcome a blind eye.

Standish's conclusions are that "the modern silver preparations are efficient in the control of gonorrheal infection of the conjunctiva, and that they have greater bactericidal properties in this disease than the laboratory experiments on other micro-organisms would lead us to expect."

\section{Standardization of Non-official Remedies.}

In the treatment of digestive disorders, due to an insufficient seeretion of saliva, the administration of the starch-digesting ferment, diastase is often recommended. Besides those malt extracts, which contain active diastase, various forms or brands of diastase are offered for sale. The source of these products differs widely and we have diastase obtained from malt, diastase extracted from the pancreas of animals and diastase of fungoid origin.

Diastase is not official in the United States Pharmacopeia and no standard of quality has been established for it. It is, therefore, but natural that the different brands as found on the market will differ very much in strength.

That this is true is shown by W. H. Blome, University of Michigan (Pharm. Rev., 1906, p. 260), who examined four commercial brands and found two of them practically worthless.

This examination brings out another important point, namely, that the activity of these preparations varies decidedly with the conditions of the experiments. Thus, a certain brand was eapable of changing a much larger quantity of starch to dextrin than was another brand, but when these two brands were judged according to the amount of starch converted to sugar then no great difference in activity was shown.

This difference in action is not surprising when the widely different sources of the ferment is considered; it points out the need of the adoption of some standard method for the valuation of diastase preparations. As far as possible, such a method should indicate their value as an aid to digestion.

"Patent Medicines" and Artificial Foods in Australia.

According to the Pharmaceutical Journal, Sept. 15, 1906, the Federal House of Representatives of Australia has passed the following motion:

1. In the opinion of this house, in the Interest of the health of the community of Australia, it is desirable that all "patent" or proprietary medicines, all Infantile and artificial foods, al medical and surgical appliances which purport to cure or to alleviate any disease to which the human frame is subject, should be critically examined on entry into the commonwealth: (a) To ascertain their contents and composition. (b) To ascertain thel value from a curative standpoint. (c) $T o$ ascertain their value as food. (d) To ascertain their value as remedial agents.

2 . It is further desirable that the exact pharmaceutical composition or construction should be set out clearly on the label or package of each bottle. tin box or parcel, and that a clear defiaition be given of the ailment they profess to cure or allevlate.

3 . In the event of the description on the bottle, tin box, package or parcel being false or misleading to the purchaser, then al such articles shall be refused admission into the commonwealth and all sucb as have been landed and not cleared shall be destroyed.

The government already possesses authority to enforce these regulations, and Sir William Lyne, minister of customs, expressed a determination to stop the importation of undesirable goods.

\section{Correspondence}

\author{
Pathologists in Hospitals for the Insane. \\ St. Peter, Minn., Oct. 22, 1906.
}

To the Editor:-Laboratories in hospitals for the insane in the Middle West are not so uncommon as the editorial in THE Journal, October 6, would imply. There are a number of them, and the laboratory in this hospital has been in existence since 1894. This laboratory was started as an adjunct to the clinical work of the hospital, rather than as a place to study the morbid histology of the brain, although the latter has not been neglected; and the "continued careful study of the rich material in these institutions" has shown us that they are unworked mines of clinical and pathologic wealth in general medicine, which have been overlooked and ignored, while time and attention has been given to the study of the morphology of the brain, and the histology of its cortex; as if in them was constituted the pathology of insanity, and with the implication that the brain existed and performed its functions independently of the rest of the organism.

Your readers may be surprised to hear that the opportunities for clinical and laboratory study in general medicine, are as great, and in some respects much greater than those existing in the average general hospital; and the knowledge to be gained of the processes in disease is much greater, because there are so many patients, and they live in the hospital continuously. While, because of the hospital regime, the ordering of the diet and occupation of the patient, and the control of his conduct; everything else but the condition to be studied can be eliminated, and this is particularly true in the study of the chronic degenerative processes in the vegetative organs. Furthermore, the work done in the laboratory has shown us that the true pathology of insanity is somatic, and has to do with the processes of nutrition and waste as they are affected by acute disease or degenerative change in the body organs.

If medical men generally would interest themselves in the clinical work in hospitals for the insane, and encourage bright young men to seek experience in general medicine in them, much would be done to put the study of insanity on a truly scientific basis; to separate psychiatry from metaphysics, and to eliminate the superstition and preconceived ideas concerning the insane that so seriously hamper the work of these institutions.

It is to be hoped, therefore, that the medical profession in Illinois will encourage other work in the laboratories to be established, besides the study of the morbid histology of the brain and general nervous system, and the manifestations of morbid psychology, which are, after all, results, not causes.

\section{H. A. Tomlinson.}

\section{Warning Against Fraudulent Insurance Agent.}

FARGo, N. D., Oct. 6, 1906.

To the Editor:-There is a man traveling about the country representing himself as an agent of the Columbian Life Insurance Company of Boston. He goes by the name of Bailey and other aliases; he sells stock and appoints agents. The offcials of the company inform me that he has swindled a great many doctors and that they have had detectives on his trail, but have not been able to get him. He is a large man, weight 240 pounds, about 5 feet 11 inches tall, dimple in chin, gray or blue eyes, poses as a Mason and an Elk. I believe publicity in Tire Journal and request for other journals to copy might save a good many doctors money and might be means of apprehending this criminal.

P. H. BuRToN, M.D.

[This case was the subject of a warning in The JournaL, May 12, 1906, page 1463.]

\section{The Necessity for Better Provision for Legal Medicine.} Philladelphia, Oct. 13, 1906.

To the Editor:-May I trespass on your space so far as to plead not guilty, or at least, non vult, to the indictments by some of your correspondents in THE Journal, October 13, page 1208. I do not think I was sarcastic; I did not intend to be. I objected to regarding lectures by a lawyer as sufficient to constitute a course in medical jurisprudence for 